\title{
Comparison of Two Different Educational Methods for Teachers' Mammography Based on the Health Belief Model
}

\author{
Esmat Heydari ${ }^{1}$, Azita Noroozi ${ }^{1,2 *}$
}

\begin{abstract}
Background: Breast cancer is the most common cancer in women. One way to decrease the burden of this cancer is early detection through mammography. This study compared the effectiveness of two different educational methods for teachers' uptake of mammography based on the Health Belief Model. Materials and Methods: The current study was a randomised trial of 120 teachers over 40 years old in two groups receiving multimedia or group education, both based on the Health Belief Model. Participants completed questionnaires before, immediately and three months after educational intervention. Mammography was evaluated before and after educational intervention. Results: The participants in the two groups were demographically similar. Comparison showed no difference noted in the scores of knowledge, perceived barriers, susceptibility, and severity constructs between two groups $(p>0.05)$. Health motivation and benefit were perceived to be higher in the group education compared to the multimedia group. There was a significant difference in mammography between two groups after the intervention ( $p=0.003$ ). Conclusions: Planning and implementation of educational program based on the Health Belief Model can raise knowledge and increase participation in mammography especially with group education.
\end{abstract}

Keywords: Mammography - breast cancer - Health Belief Model - education - teachers

Asian Pac J Cancer Prev, 16 (16), 6981-6986

\section{Introduction}

Breast cancer is the most common cancers and the main cause of mortality from cancer among female around the world (Marinho et al., 2003). In Iran, as well, breast cancer is at the top of female cancers and it is totally $16 \%$ of all cancers (Pormehr et al., 2010). In fact, in Iran, incidence of breast cancer is 22 in 100000 and its prevalence is 120 in 100000 women between the ages of 15 to 84 (Mousavi et al., 2007). Breast cancer has different negative effects which influence quality of life (Chopra et al., 2012).

A way to decrease this disease is early detection of it through screening. Screening program includes breast self-examination, clinical breast examination, and mammography (Dean and Ginloano, 2003). Considering sensitivity and specificity limitations of breast selfexamination and clinical breast examination, mammogram is the most effective ways of early diagnosis (Tobin, 1998 ) and is able to diagnose any mass 2-4 years before it gets palpable (Greenall, 1994). Different studies in Iran show that the amount of mammography is very low among Iranian women and it is reported around 3.3-9.1\% (Mahoori et al., 2003; Farshbaf et al., 2010; Pormehr et al., 2010).

Numerous studies have been carried out to find out effective factors on mammography. They indicate that personal factors are the most important factors affecting screening of breast cancer (Lagerlund et al., 2000; Avci et al., 2009; Hatefnia et al., 2010). Therefore, Health Belief Model (HBM) is a cognitive model which is used to intervention of this behavior (Tastan et al., 2011). Based on this model, if people believe that they are susceptible to disease such as breast cancer (perceived susceptibility), understand the risk depth and severity of its different complications in their life (perceived severity), consider proposed ways including mammography useful in decreasing risk or severity of the disease (perceived benefits), and be able to overcome obstacles for action, including cost and pain (perceived barriers), they will be more likely to contribute to health improvement programs (Champion, 1993; Aydin et al., 2008).

On the other hand, performing educational programs in order to change one's health belief through different methods including group education and multimedia education is possible. In multimedia education, learning process is active and as different senses are applied for more learning and practices in order to obtain mastery learning, it is an interesting and useful method. Group education is defined as small group interaction and exchange. It is necessary to diagnose a problem, help someone make a plan or decision, or direct someone to an appropriate resource. In group education the trainees are face to face, analyzing and discussing over various 
dimensions of a health issue is possible which itself results in information exchange and integration (Parvanta and Nelson, 2011).

Efficiency of multimedia (Murray et al., 2001; Valdez et al., 2001; Siavash et al., 2011) and group (Hall et al., 2005; Gursoy et al., 2009; Hatefnia et al., 2010) education has been investigated and supported by several studies. Despite various studies about education's effect on mammography, no investigations have been found on efficiency of multimedia education and its comparison with group education according to HBM. Therefore, the researchers intend to compare efficiency of group education and multimedia education so that an appropriate education method to change health belief and behavior relating breast cancer screening is recognized.

\section{Materials and Methods}

\section{Study design}

The current study is a random clinical trial which has been carried out since November to March, 2015 in 21 elementary schools in Bushehr, a southwestern province in Iran.

The participants include female elementary school teachers. The inclusion criteria were older than 40 years, not pregnant or breast-feeding, not having breast cancer or other types of cancers, not having family history of breast cancer, not having breast biopsy experience and mammography in the past three years.

The sample size was estimated based on similar study (Avci et al., 2009), 52 subjects for each group and with considering attrition rates $(25 \%)$ in three months fallow up, about 65 subjects were required for each groups (group education and multimedia education). Teachers from the various elementary schools were selected to be in the same groups so as to discourage interaction between teachers or keep it at a minimum. When separating the participants into the group education or the multimedia education, control variables (age, breast cancer history in the family, information about breast cancer and mammography, and etc) and school criteria were considered. After group assignments were completed, control variables and demographic characteristics were noted to be similar between the two groups.

For group education, 65 subjects initially entered the study of which 5 subjects did not attend the second meeting. In multimedia education, 65 subjects initially entered the study of which 2 subjects quitted due to lack of time and 3 subjects submitted imperfect data questionnaire.

\section{Methods and data collection}

In group education, after getting the written consent, we asked them to fill out the questionnaire prior to training. The subjects were then trained by the researcher in two sessions with one week interval. Each educational session lasted 45-60 $\mathrm{min}$. In the first session, the subjects were provided with some information about breast anatomy, and warning against breast cancer (increasing susceptibility). Moreover, subjects presented some examples about their friends and relatives who without any special disease background or without family history of breast cancer had got breast (or other) cancer and in this way made their group susceptible. Subsequently, the depth and severity of complications and results of late diagnosis of the disease (perceived severity) were also discussed. Those who had presented their opinions about susceptibility were asked to explain individual, family, and financial effects of cancer on the samples they had discussed. At last, a general discussion about the session and the results were offered through an oral presentation and PowerPoint slides.

In the second session (after one week), it was initially discussed about benefit of mammography. Then, through slide show, its performance process was explained. The subjects were also asked to offer a list of problems and barriers they imagined in the process of mammography. Accordingly, it was attempted to eliminate such barriers through required explanations. Discussion and conclusion of this session were also carried out through oral presentation and PowerPoint slides. At last, the subjects answered the questions on knowledge and constructs of HBM.

In multimedia education, after giving consent and filling out the questionnaires, the subjects received the trainings which were similar to those of group education and planned by the researchers based on HBM through $\mathrm{CD}$, and educational SMS to their cell phones. Information about breast anatomy and structure, the process of breast cancer beginning, making susceptibility against the risk of breast cancer, perceiving severity and seriousness of the disease, benefits and barriers of mammography were presented through an educational CD. The CD could be automatically played and contained different parts presenting the educational subject with a click. Moreover, the subjects were weekly received one or two educational SMS about breast cancer and mammography usefulness in the first month. A week after receiving the educational package, the subjects answered the questions about knowledge and constructs of HBM again.

A month after the beginning of the program, as cues to action, a SMS was sent to subjects of group education and multimedia education to remind mammography.

Three months later, besides filling out the questionnaires relating knowledge and constructs of HBM, the samples were asked if they had performed mammography and their screening results were taken.

\section{Instruments and measures}

Data collection tool in this study was Champion Questionnaire (Taymoori et al., 2009). It consists of four sections. The first section includes personal information with 20 questions about age, educational level of the subject and her husband, marital status, number of pregnancies and children, number of abortions, menstrual age, and etc.

The second section contains questions about knowledge along with 15 multiple-choice questions about predisposing factors of breast cancer, for each true answer a positive point and for each false answer no point was appointed. The reliability of this section according to Kuder Richardson coefficient was 0.78.

The third section relates questions about constructs 
of HBM. It contains 30 questions relating subject's belief on perceived susceptibility (5 items), perceived severity of breast cancer ( 7 items), perceived benefits (6 items), perceived barriers ( 5 items), and health motivation ( 7 items). All items in the five subscales were scored using a Likert scale ranging from 1 (strongly disagree) to 5 (strongly agree), as higher ranking on the Likert scale indicates greater agreement with the health beliefs that were assessed (Hall et al., 2005). In this study, the reliability of these subscales according to Cronbach's alpha coefficients ranged from 0.72 (health motivation) to 0.89 (susceptibility).

The fourth section relates to mammography which is answered by the subjects through a yes/no question. If the answer is no, intention to perform mammography is asked by another question.

The data were analyzed by the statistical package for social sciences software (SPSS) version 16.0. Descriptive statistics, Chi-square test, t-test, t paired test, repeated measurement ANOVA, Mann- Whitney U and McNemar test were used for data analysis.

\section{Ethical principles}

The aim of the study was verbally explained to the potential participants who met the inclusion criteria. The participants were told that they could withdraw from the study at any time and that all information would be kept secret and anonymous. The required permissions were obtained from the Vice-Chancellor for research of Bushehr university of medical sciences, department of education in Bushehr city, and the managements of the relevant schools. Also, the study was approved by the university ethics committee.

\section{Results}

A total of 120 teachers ( $\mathrm{N}=60$ in each group) entered in this study. The participants of multimedia education and group education were demographically similar.
For instance, the average age of multimedia education group was $44.92 \pm 4.34$, while the average age in group education was $45.48 \pm 4.69(\mathrm{p}=0.494)$. Of the entire study sample, $14.2 \%(n=17)$ of participants knew about breast cancer. We found that $65 \%(n=78)$ of participants in two groups knew about mammography while only $18.3 \%$ $(n=22)$ had history of mammography. Other demographic characteristics that related to mammography were shown in Table 1.

We also found that the women in the group and multimedia education groups were similar in their health beliefs related to mammography before education, but the difference between two groups was statistically significant after training in several constructs (Table 2).

Comparison of pre- and post-test (immediate and 3 months later) results in multimedia group by repeated measurement ANOVA found that changes occurred in the Knowledge and perceived barriers. The results demonstrated an increase in knowledge $(\mathrm{p}<0.001)$ as well as the barrier decreased statistically significant ( $\mathrm{p}=0.007)$. Likewise, there were no statistically significant changes in the subscales about perceived susceptibility, severity, benefit of mammography and health motivation ( $p>0.05)$.

However, in the group education, the results showed that there were significant changes between the pre- and post-test scores for the knowledge, health motivation, perceived benefit and barriers constructs, as the barriers decreased $(\mathrm{p}<0.006)$ and knowledge and health motivation increased; benefits of mammography were perceived to be higher compared to pre-test at the post-test $(\mathrm{p}=0.003)$.

Comparison of two groups during the time showed that no difference noted in the scores of the knowledge, perceived barriers, susceptibility, and severity constructs between two groups ( $>0.05$ ), but health motivation and benefit were perceived to be higher at the group education compared to multimedia group (Table 2).

About intention of mammography, from 60 participants in each groups after education, $56(93.33 \%)$ of group education and $50(83.33 \%)$ of multimedia group had

Table 1. Demographic Features and Breast Cancer Screening Behavior in Two Groups Prior to Training

\begin{tabular}{|c|c|c|c|c|c|c|c|}
\hline \multirow[t]{2}{*}{ Demographic variables } & & \multicolumn{2}{|c|}{ Multimedia education } & \multicolumn{2}{|c|}{ Group education } & \multirow[t]{2}{*}{ statistics } & \multirow[t]{2}{*}{ P-value } \\
\hline & & $\mathrm{N}$ & $\%$ & $\mathrm{~N}$ & $\%$ & & \\
\hline \multirow[t]{3}{*}{ Marital status } & Married & 57 & 93.3 & 56 & 95 & 0.34 & 0.84 \\
\hline & Single & 1 & 3.3 & 2 & 1.7 & & \\
\hline & Widowed, Divorced & 2 & 3.3 & 2 & 3.3 & & \\
\hline \multirow[t]{2}{*}{ Educational level } & Diploma & 27 & 41.7 & 25 & 45 & 0.14 & 0.71 \\
\hline & Bachelor or master & 33 & 58.3 & 35 & 55 & & \\
\hline \multirow[t]{2}{*}{ Familial history of breast cancer } & Yes & 6 & 10 & 6 & 10 & ----- & ------ \\
\hline & No & 54 & 90 & 54 & 90 & & \\
\hline \multirow[t]{3}{*}{ Information about cancer } & Has information & 9 & 13.3 & 8 & 15 & 2.16 & 0.34 \\
\hline & Has no information & 4 & 15 & 9 & 6.7 & & \\
\hline & Has some deal information & 47 & 71.7 & 43 & 78.3 & & \\
\hline \multirow[t]{2}{*}{ Information about mammography } & Has information & 41 & 61.7 & 37 & 68.3 & 0.59 & 0.44 \\
\hline & Has no information & 19 & 38.3 & 23 & 31.7 & & \\
\hline \multirow[t]{2}{*}{ Has undergone mammography } & Yes & 13 & 15 & 9 & 21.7 & 0.89 & 0.34 \\
\hline & No & 47 & 85 & 51 & 78.3 & & \\
\hline \multirow[t]{2}{*}{ Information about BSE } & Has information & 34 & 58.3 & 35 & 56.7 & 0.034 & 0.85 \\
\hline & Has no information & 26 & 41.7 & 25 & 43.3 & & \\
\hline \multirow[t]{2}{*}{ BSE practice } & Performs BSE & 30 & 60 & 36 & 50 & 1.212 & 0.27 \\
\hline & Doesn't perform BSE & 30 & 40 & 24 & 50 & & \\
\hline
\end{tabular}


Table 2. Constructs' Scores of Health Belief Model During Intervention

\begin{tabular}{|c|c|c|c|c|}
\hline Constructs & Times & $\begin{array}{l}\text { Multimedia education } \\
\qquad \mathrm{M} \pm \mathrm{SD}\end{array}$ & $\begin{array}{l}\text { Group education } \\
\quad \mathrm{M} \pm \mathrm{SD}\end{array}$ & P Value \\
\hline Knowledge & $\begin{array}{l}\text { Before intervention } \\
\text { After intervention } \\
3 \text { months later } \\
\text { P Value }\end{array}$ & $\begin{array}{c}5.32 \pm 3.89 \\
12.33 \pm 2.61 \\
11.60 \pm 2.95 \\
0\end{array}$ & $\begin{array}{c}5.32 \pm 3.84 \\
12.93 \pm 1.98 \\
12.93 \pm 1.70 \\
0\end{array}$ & 0.128 \\
\hline Perceived Susceptibility & $\begin{array}{l}\text { Before intervention } \\
\text { After intervention } \\
3 \text { months later } \\
\text { P Value }\end{array}$ & $\begin{array}{c}11.98 \pm 4.81 \\
12.96 \pm 5.25 \\
12.38 \pm 5.03 \\
0.334\end{array}$ & $\begin{array}{c}10.71 \pm 3.90 \\
11.65 \pm 4.49 \\
11.90 \pm 1.70 \\
0.092\end{array}$ & 0.56 \\
\hline Perceived Severity & $\begin{array}{l}\text { Before intervention } \\
\text { After intervention } \\
3 \text { months later } \\
\text { P Value }\end{array}$ & $\begin{array}{c}22.97 \pm 6.30 \\
22.37 \pm 7.18 \\
22.23 \pm 6.34 \\
0.522\end{array}$ & $\begin{array}{c}22.45 \pm 7.27 \\
21.93 \pm 6.97 \\
20.87 \pm 6.94 \\
0.128\end{array}$ & 0.614 \\
\hline Perceived benefits & $\begin{array}{l}\text { Before intervention } \\
\text { After intervention } \\
3 \text { months later } \\
\text { P Value }\end{array}$ & $\begin{array}{c}26.83 \pm 3.29 \\
26.96 \pm 3.27 \\
26.26 \pm 3.49 \\
0.4\end{array}$ & $\begin{array}{c}26.50 \pm 3.58 \\
28.02 \pm 2.86 \\
27.77 \pm 2.77 \\
0.003\end{array}$ & 0.029 \\
\hline Perceived barriers & $\begin{array}{l}\text { Before intervention } \\
\text { After intervention } \\
3 \text { months later } \\
\text { P Value }\end{array}$ & $\begin{array}{c}13.17 \pm 3.75 \\
11.65 \pm 3.73 \\
11.95 \pm 4.19 \\
0.007\end{array}$ & $\begin{array}{c}13.38 \pm 4.28 \\
12.48 \pm 5.14 \\
11.43 \pm 4.33 \\
0.006\end{array}$ & 0.222 \\
\hline Health Motivation & $\begin{array}{l}\text { Before intervention } \\
\text { After intervention } \\
3 \text { months later } \\
\text { P Value }\end{array}$ & $\begin{array}{c}30.42 \pm 3.12 \\
30.52 \pm 4.38 \\
30.13 \pm 3.59 \\
0.755\end{array}$ & $\begin{array}{c}29.62 \pm 4.57 \\
30.95 \pm 2.79 \\
31.20 \pm 2.61 \\
0.01\end{array}$ & 0.044 \\
\hline
\end{tabular}

intention of mammography ( $\mathrm{p}=0.088)$, but 3 months later, $48(80 \%)$ of group training and $33(55 \%)$ of multimedia group performed mammography $(\mathrm{p}=0.003)$.

\section{Discussion}

The current study revealed that group education leaded to promote knowledge, further understanding of the benefits of mammography, reducing barriers to mammography and promoting health motivation; but multimedia education just leaded to promote knowledge and to reduce understanding from mammography barriers.

There was a significant difference between two groups during the time only considering the perceived benefits and health motivation, so that the group education had been more effects on the people motivation and their understanding of mammography benefits. From the intention of mammography, both groups made a desire to perform mammography, but the women performed more mammography significantly in the group education.

In several studies which different educational methods including individual, group, and multimedia education were used, all of them leaded to increase knowledge about breast cancer which is consistent with the findings of the current study (Hall et al., 2005; Avci et al., 2009; Gursoy et al., 2009; Hajian et al., 2011; Rezaeian et al., 2014).

Moreover, using multimedia increased knowledge about prenatal care in the pregnant women (Mohamadirizi et al., 2013) and knowledge in the field of cancer in people with prostate cancer (Huber et al., 2013) which shows the effectiveness of different educational methods to promote knowledge level.

About perceived severity of disease, the results demonstrate that teachers perceived the risk of breast cancer to be moderate both before and after education. These constructs measure the level of acceptance that a woman presents in the event that she develops breast cancer. The reason for the lack of change after the training is that unknown future events are accepted as part of the traditional approach (Avci et al., 2009). Although the teachers might be living on the middle or upper level of socioeconomic conditions, they may have been affected by the more traditional attitudes based on God locus of control in their current daily lives. Therefore long term education may be required to change this traditional approach. This finding is consistent with the result of Avci et al study with two educational methods through model and video education (Avci et al., 2009).

From the perceived sensitivity, the people deny their susceptibility to disease because of the fear of cancer in the Iranian culture, so the education could not make any changes on this individual belief. Also, the group education on the Iranian women could not make any changes in the perceived sensitivity in Hajian's study which represent the difficulty of changing this health belief in the Iranian women (Hajian et al., 2011). In Gursoy et al study, the group education and using printed materials could not make any changes in the sensitivity which confirm the current finding (Gursoy et al., 2009). Ceber has also reported some findings similar to the current study (Ceber et al., 2010). But this finding is contrast with Rezaeian study which had educations with more sessions which shows the necessity of long-term educations in this field.

From the perceived benefits, the multimedia education did not make any changes in this field during the time, but the group education with the discussion could promote the understanding from the benefits of mammography which is consistent with Rezaeian's findings (Rezaeian et 
al., 2014). But in Gursoy's study, the score of perceived benefits in the group education had not significant increase in spite of the current study which can be the result of the kind of applied education (Gursoy et al., 2009) and because there is not the possibility of group discussion in multimedia education, the reason of not promoting perceived benefits in multimedia group can be attributed to this factor which is consistent with Avci study (Gursoy et al., 2009). Performing further researches about the effectiveness of multimedia education is necessary because of the limited studies.

From the perceived barriers, the teachers of both groups had health insurance, so they were not concerned about the financial problems, secondly, giving turn to people contributed in the study was accelerated with a letter of introduction in their hands, in other word, both educational groups reduced the people's understanding from other barriers significantly. This finding is consistent with the results of several studies about the effectiveness of group education (Gozum et al., 2010; Hajian et al., 2011; Rezaeian et al., 2014), but the group education had not any effect on the people's understanding from the barriers of breast self-examination because of the short duration of education in Avci et al study. In Avci el at study, the multimedia education did not reduce the people's understanding from barriers of mammography and breast self-examination in spite of the current study (Avci et al., 2009) which these contrasts can be due different methodologies of the studies. In Noohi and Mirzazadeh study, the multimedia education changed the self- management of diabetic patients which is consistent with the finding of the current study (Noohi et al., 2011) of course, the patterns of the behavior change were not used in this study, so further researches are necessary in the context of HBM through multimedia method due to the limited studies.

Education with group method made a significant increase in the health motivation, but multimedia education was ineffective in this area. This finding is consistent with the results of several studies (Avci et al., 2009; Hajian et al., 2011; Rezaeian et al., 2014).

Education with both group and multimedia methods could make an intention to perform mammography, but group education with group discussion through making further changes in health beliefs such as more understanding of the benefits and making health motivation leaded to perform mammography significantly. In Valdz's study about the effect of multimedia education on mammography among low income women, it was found that about $42 \%$ of women who had mammography or planning to perform it, their decision was attributed to the educational program (Valdez et al., 2001). In Avci study, the multimedia education leaded to increase breast self-examination (Avci et al., 2009). In several studies, the effectiveness of multimedia education in diabetic patients' quality of life (Boren et al., 2006; Noohi et al., 2011; Abumasoudi et al., 2015), patients with prostate cancer (Baraz et al., 2014) and patients under hemodialysis (Huber et al., 2013) has approved. Moreover, in Hatefnia's study, the effectiveness of group education to perform mammography has been reported which is consistent with the current study (Hatefnia et al., 2010), but in Hajian's study, the group education could not lead to increase mammography which can be due to hold group education sessions as a lecture without group discussion (Hajian et al., 2011). However, in other study revealed that group education with discussion to promote life quality of the patients with hypertension had been more effective than multimedia education which partly confirms recent findings (Aghajani et al., 2013).

Some of the limitations of this study can be the short follow-up period, but if it was long (for instance six months), more people might have found enough time for mammography. Secondly, the examination of healh beliefs and knowledge was as self-report which sometimes tend to be overestimated; of course, due to the both groups were examined with a method, this fact is true for both groups.

In conclusion, Generally, it can be said that both educational methods had the same influence on the awareness of teachers in the field of breast cancer and had significant role to create a plan to mammography and also its performance by reducing the barriers. Of course, the group education had been more effective to perform mammography with making more changes in the health beliefs. So, it can be recommended that due to the simplicity, reproducibility and cost-effectiveness of the multimedia education based on HBM, to inform teachers and to make a plan to mammography, this educational method can be used which will also cause to perform mammography significantly, then the people who have not decided to perform mammography with this method can be taught with group method which is a time-consuming method.

\section{References}

Aghajani M, Mirbagher Ajorpaz N, et al (2013). Effect of self - care education on quality of life in patients with primary hypertension: comparing lecture and educational package. Nurs Midwifery Stud, 2, 71-6.

Austin Boren S, Gunlock TL, Krishna S, Kramer TC (2006). Computer-aided diabetes education: A synthesis of randomized controlled trials. AMIA Annu Symp Proc, 2006, 51-55.

Avci IA, Gozum S (2009). Comparison of two different educational methods on teachers' knowledge, beliefs and behaviors regarding breast cancer screening. Eur J Oncol Nurs, 13, 94-101.

Aydin IA (2008). Factors associated with breast self- examination practices and beliefs in female workers at a Muslim community. Eur J Oncol Nurs, 12, 127-33.

Baraz S, Zarea K, Dashtbozorgi B (2014). Comparing the effect of two educational programs on the quality of life of hemodialysis paᄀtients in iran. Iran Red Crescent Med $J, \mathbf{1 6}, 75-84$.

Ceber E, Turk M, Ciceklioglu M (2010). The effects of an educational program on knowledge of breast cancer, early detection practices and health beliefs of nurses and midwives. J Clin Nurs, 19, 236371.

Champion VL (1993). Instrument refinement for breast cancer screening behaviors. Nurs Res, 42, 139-43.

Chopra I, Kamal Kh (2012). A systematic review of quality of life instruments in long term breast cancer survivors. Health Qual life Outcomes, 10, 2-15. 
Esmat Heydari et al

Dean TN, Ginloano AE (2003). Breast cancer. In: Jonathan S. Berek MD. Novak's gynecology. Philadelphia: Wolters Kluwer Company. 546-7.

Farshbaf K, Shahnazi M (2010). Breast Cancer Screening (breast self-examination, clinical breast exam, and mamography) in women referred to health centers in Tabriz, Iran. Indian $J$ Med Sci, 64, 149-62.

Gozum S, Karayurt O, Kav S, Platin N (2010). Effectiveness of peer education for breast cancer screening and health beliefs in eastern Turkey. Cancer Nurs, 33, 21320.

Greenall MJ (1994). Breast. In: Morris PJ and Malt RA. Oxford textbook of surgery. Oxford: oxford Medical Publications, 808.

Gursoy AA, Hindistan S, Nural N, et al (2009). Comparison of three educational interventions on breast self-examination knowledge and health beliefs. Asian Pac J Cancer Prev, 10, 765-72.

Hajian S, Vakilian K (2011). Effects of education based on the health belief model on screening behavior in high risk women for breast cancer, Tehran, Iran. Asian Pac J Cancer Prev, 12, 49-54.

Hall CP, Wimberley PD, Hall JD, et al (2005). Teaching breast cancer screening to African American women in the Arkansas Mississippi river delta. Oncol Nurs Forum, 32, 85763.

Hatefnia E, Niknami S, Bazargan M, et al (2010). Correlates of mammography utilization among working Muslim Iranian women. Health Care Women, 31, 499-514.

Huber J, Ihrig A, Yass M, et al (2013). Mul-timedia support for improving preoperative patient education: a randomized controlled trial using the example of radical pros $\neg$ tatectomy. Ann Surg Oncol, 20,15-23.

Huber J, Ihrig A, Yass M, et al (2013). Mulᄀtimedia support for improving preoperative patient education: a randomized controlled trial using the example of radical pros $\neg$ tatectomy. Ann Surg Oncol, 20,15-23.

Khan MA, Shah S, Grudzien A, et al (2011). A diabetes education multimedia program in the waiting room setting. Diabetes Ther, 2, 178-88.

Lagerlund M, Hedin A, Sparén P (2000). Attitudes, beliefs, and knowledge as predictors of nonattendance in a Swedish population-based mammography screening program. Prev Med, 31, 417-28.

Mahoori KH, Sadeghi Hasanabadei A, Talei AR (2003). Knowledge and practice of women referring to Shiraz health centers about breast cancer screening. Med J Hormozgan, 7, 68-75. (Persian)

Marinho LAB, Costa-Gurgel MS, Cecatti JG, Osis MJD (2003). Knowledge, attitude and practice of breast self-examination in health centers. Rev Sauide publica, 37, 576-82.

Mohamadirizi S, Fahami F (2013). The effect of E-Learning education on primipar women's knowledge about neonatal care. Iran J Neonatol, 4, 24-27.

Mousavi SM, Montazeri A, Mohagheghi MA, Jarrahi A, Harirchi I (2007). Breast cancer in Iran: an epidemiological review. $J$ Breast Cancer, 13, 383-391.

Murray E, Davis H, Tai SS, Coulter A, Gray A, Haines A (2001). Randomised controlled trial of an interactive multimedia decision aid on benign prostatic hypertrophy in primary care. $B M J, 323,493-4$.

Noohi E, Khandan M, Mirzazadeh A (2011). Effective of electronic edu 7 cation on knowledge attitude and self-care in patient's diabetic type 2 refer to diabetic center of Kerman University of medical science. Iranian J Nurs Res, 6,73-80.

Parvanta C, Nelson DE, Parvanta SA, Harner RN (2011). Essentials of public health communication. USA: Jones \& Barlett Learning, 181-205.
Rezaeian M, Sharifirad G, Mostafavi F, Moodi M, Abbasi MH (2014). The effects of breast cancer educational intervention on knowledge and health beliefs of women 40 years and older, Isfahan, Iran. J Edu Health Promot, 3, 4-10.

Salimi Pormehr S, Kariman N, Sheykhan Z, Alavi Majd H (2010). Test Investigation of breast cancer screening performance and affecting factor in women refferd to Ardebils health and medical centers , 2009. J Ardabil Univ Med Sci, 10, 310-8.

Sheikh Abumasoudi R, Ghamari Zare Z (2015). Self-care program with multimedia software support effect on quality of life in patients with diabetes type II. Jundishapur $J$ Chronic Dis Care, 4, 22536.

Siavash VY, Tadrisi SD, Ghayyem S, Ebadi A, Daneshmandi M, Saghafi NM (2011). Comparing the effect of Triage education in lecture and multimedia software on nurses learning. Iran J Crit Care Nurs, 4, 7-12.

Tastan S, Iyigun E, Kilic A, Unver V (2011).Health beliefs concerning breast self-examination of nurses in Turkey. Asian Nurs Res, 5, 151-6.

Taymoori P, Berry TR (2009). The validity and reliability of Champion's Health Belief Model scale for breast cancer screening behaviors among Iranian Women. Cancer Nurs, 32, 465-72.

Tobin MJ (1998). Breast cancer. In: Taylor RB. Family medicine principles and practice.5th ed. New York: Spring, 934-8.

Valdez A, Banerjee K, Fernandez M, Ackerson L (2001). Impact of a multimedia breast cancer education intervention on use of mammography by low-income Latina's. J Cancer Edu, 16, 221-5. 